\title{
Acquisition of a temporal discrimination by human subjects'
}

\author{
DAVID E. CARTER AND GLENN J. MacGRADY \\ COLUMBIA UNIVERSITY
}

Acquisition of a button-pressing response for three values of a DRL schedule was observed for 12 human Ss under instructions to win as many points, indicated by a flashing light, as possible. All Ss showed a rapid development of a temporal discrimination and a rapid transition from DRL 3 sec. to DRL $6 \mathrm{sec}$. to DRL $10 \mathrm{sec}$. Several characteristics of stable DRL behavior were observed to be similar to those found with animal Ss.

A number of recent studies have employed differential reinforcement of low rates of responding (DRL) to study the acquisition and maintenance of temporal discriminations by animal Ss. The only responses in a DRL schedule which produce reinforcement are those which follow some specified minimum period without the emission of the response. For example, in a 10-sec. DRL schedule every response made by $S$ after a pause of at least 10 sec. is reinforced. When a response occurs less than $10 \mathrm{sec}$. after the preceding response, the clock which times the reinforcement contingency is reset to zero. Such schedules of reinforcement typically produce low, steady rates of responding when rats are used as Ss (Farmer \& Schoenfeld, 1964).

Other experiments have also employed DRL schedules with human Ss. However, the primary interest of these studies has been in the development of collateral behavior (Bruner \& Revusky, 1961; Kapostins, 1963) and in the use of a DRL baseline for the assessment of other experimental operations (e.g., Dews \& Morse, 1958; Weiner, 1964). Such studies have emphasized the characteristics of stable DRL behavior. The present paper reports data on acquisition of stable DRL behavior by human Ss within a single, short experimental session. Subjects

Eleven male and one human female $S$, ranging in age from 18 to approximately 50, were asked to serve in the experiment without pay. Only S-4 had any acquaintance with DRL schedules and none of the Ss had any previous experience serving in similar experiments. Apparatus

The Ss were seated in an audiometric room (Industrial Acoustics, Model 400 ). In front of the $S$ was a panel containing four pilot lights and four pushbuttons. Only one of the lights was used to indicate the occurrence of a reinforcement. The overhead light in the experimental room was turned off throughout the session in order to increase the likelihood that $S$ would see the light and to prevent $S$ from using a watch to time the responses. Only one of the buttons was effective in making a response. The other buttons were covered with tape so that $S$ could find the appropriate button in the dark.

One of the interests of the Es in the development of a DRL baseline was for use in a study of stimulus control. For this reason the data reported here were obtained with a procedure in which the DRL schedule was in effect for fixed periods of time alternating with short time-out periods in which $\mathrm{E}$ could change discriminative stimuli. A tone of $1000 \mathrm{cps}$ at $60.8 \mathrm{db}$ re: $0.0002 \mathrm{dynes} / \mathrm{cm}^{2}$ was presented to $\mathrm{S}$ binaurally through earphones to indicate periods when reinforcement could be obtained.

All features of the experiment were programmed using standard relay apparatus. Responses and reinforcements were recorded on electro-mechanical counters and a Gerbrands cumulative recorder which was turned off during the time-outs.

Procedure

All Ss were run individually under the following written instructions:

"On the panel in front of you are a button, a light, and a pair of earphones. Put the earphones on and leave them on until the end of the experiment. When the tone comes on you job will be to turn on the light by pressing the button. You win a point every time you press the button and the light goes on, but you will receive no credit for button presses which do not turn on the light. Your point score is a measure of your ability to learn quickly and you will be compared with other students at the end of the experiment.

"The overhead light in the booth will remain off throughout the experiment so that you will always be able to see the light clearly each time you win a point.

"Be sure that you understand what your job is. If you are not sure, read the instructions again. Remember that the experiment will begin as soon as you hear a tone over the earphones.

"Do not, under any circumstances, open the door of the booth during the experiment. If you do, it will be necessary to start the experiment over again."

When $\mathrm{S}$ had finished reading the instructions $\mathrm{E}$ pointed out which button and light were to be used in the experiment. If $S$ asked how long the experiment would last he was told that it depended on his performance during the session.

Each $S$ was exposed to DRL $3 \mathrm{sec}$. for a minimum of $15 \mathrm{~min}$., to DRL 6 sec. for a minimum of $15 \mathrm{~min}$., and to DRL $10 \mathrm{sec}$. for 30 min. One $S$ was given an additional $15 \mathrm{~min}$. of DRL 3 sec. and three Ss were kept on DRL $6 \mathrm{sec}$. for an extra $15 \mathrm{~min}$. This was done only when the Es thought that additional improvement in the temporal discrimination might occur. None of the Ss were given regular reinforcement preceding the introduction of DRL.

Periods in which reinforcement could be obtained lasted for 2.5 min. and alternated with $30-\mathrm{sec}$. time-out periods. When the DRL schedules were in effect a pure tone of $1000 \mathrm{cps}$ at $60.8 \mathrm{db}$ re: 0.0002 dynes $/ \mathrm{cm}^{2}$ was presented binaurally to $S$ through the earphones. This discriminative stimulus was turned off for the duration of the time out. All schedule changes were made during the timeouts without interrupting the experiment.

Results and Discussion

The cumulative records of the entire session for four typical Ss are presented in Fig. 1. Three of the Ss shown in Fig. 1 begin the session with a rate of responding which is sufficiently low after a few unreinforced responses to obtain close to the maximum number of possible reinforcements. S-2 begins with a slightly higher rate than the other Ss and obtains fewer reinforcements during the first $6 \mathrm{~min}$. A sharp decrease in rate then occurs and almost all of the responses which follow are reinforced.

Three of the Ss in Fig. 1 show a rapid transition from DRL $3 \mathrm{sec}$. to DRL $6 \mathrm{sec}$. S-2 begins the DRL $6 \mathrm{sec}$. phase of the experiment with a rate approximately equal to that under DRL $3 \mathrm{sec}$. and only four reinforcements 


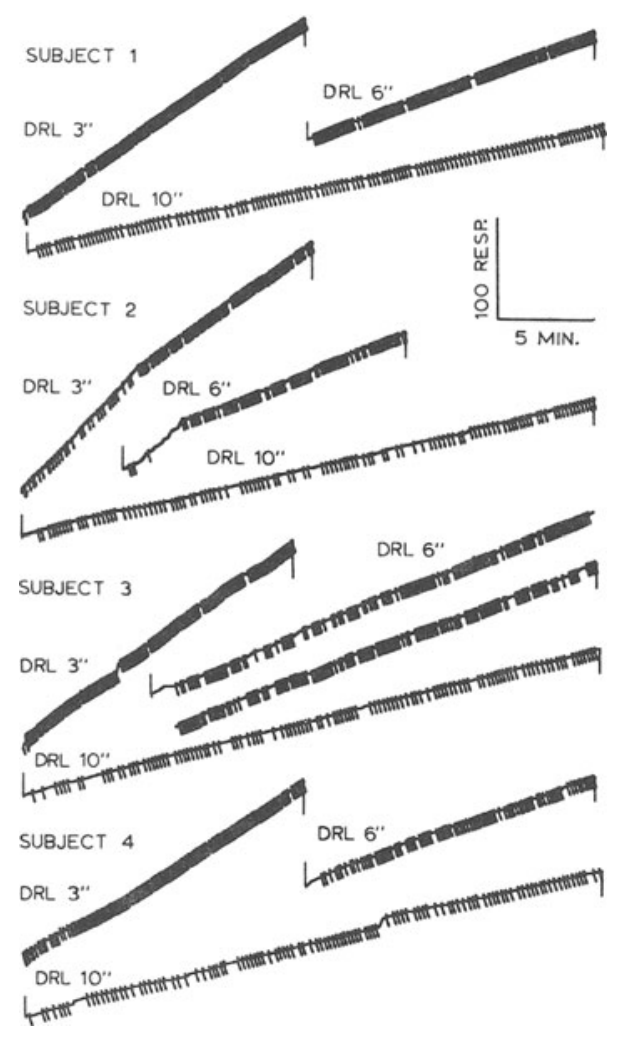

Fig. 1. Cumulative records of the entire session for four typical Ss on three values of a DRL schedule. Downward pips of the recorder pen indicate the occurrence of reinforcements

are obtained in the first $3.5 \mathrm{~min}$. An abrupt decrease in rate then occurs resulting in near optimal DRL behavior. Transition from DRL 6 sec. to DRL 10 sec. is rapid for all Ss.

The behavior under DRL 10 sec. exhibited in Fig. 1 shows two characteristics which are typically found with animal Ss. Occasional short bursts of responding may be observed in the record made by $\mathrm{S}-4$. These bursts were also observed in one other $\mathrm{S}$ not shown in Fig. 1. However, this characteristic does not appear to be as com- mon during the early stages of training with human Ss under the present procedure as it does with most studies employing animal Ss.

Figure 1 also shows several instances of a series of successive reinforced responses separated by a series of near-criterion responses. This is particularly true in the 10-sec. DRL records of S-2 and S-3. These near-criterion responses have also been found to be common with animal Ss (Farmer \& Schoenfeld, 1964).

One characteristic of DRL behavior necessary for rapid transition to a higher $D R L$ value must be rapid extinction of the responses maintained by the previous schedule. It has been shown (Carter, 1966) that extinction following DRL conditioning is rapid when the temporal discrimination is accurate enough so that most of S's responses are reinforced. This is clearly the case in the present study under each of the DRL schedules.

It was not possible to observe collateral behavior during the experiment because the Ss were located in a darkened room. However, at the end of the session all Ss reported counting and one $S$ reported swinging his arm as a pendulum and counting the oscillations.

\section{References}

Bruner, A., \& Revusky, S. H. Collateral behavior in humans. $J$. exp. Anal. Behav., 1961, 4, 349-350.

Carter, D. E. Extinction and reconditioning of a temporal discrimination in the albino rat. Paper read at Eastern Psychological Association, New York, April, 1966.

Dews, P. B., \& Morse, W. H. Some observations on an operant in human subjects and its modification by dextro amphetamine. $J$ exp. Anal. Behav., 1958, 1, 359-364.

Farmer, J., \& Schoenfeld, W. N. Inter-reinforcement times for the bar-pressing response of white rats on two DRL schedules. $J$. exp. Anal. Behav., 1964, 7, 119-122.

Kapostins, E. E. The effects of DRL schedules on some characteristics of word utterance. J. exp. Anal. Behar', 1963, 6, 281290.

Weiner, H. Conditioning history and human fixed-interval performance. J. exp. Anal. Behav., 1964, 7, 383-385.

\section{Note}

1. Reprints may be obtained from David E. Carter, Department of Psychology, 470 Schermerhorn Hall, Columbia University, New York, N. Y. 10027. 